\title{
Carbonylated proteins accumulated as vitality decreases during long-term storage of beech (Fagus sylvatica L.) seeds
}

\author{
Ewa Marzena Kalemba · Stanisława Pukacka
}

Received: 13 August 2013/Revised: 29 November 2013/ Accepted: 11 December 2013/Published online: 31 December 2013

(C) The Author(s) 2013. This article is published with open access at Springerlink.com

\begin{abstract}
Key message Carbonylation of proteins associated with a stress response may contribute to the lowered viability of naturally aged beech seeds, especially the desiccation tolerance-associated proteins and USP-like protein.

Abstract Proteins are modified by a large number of reactions that involve reactive oxygen species-mediated oxidation. The direct oxidation of amino acids produces 2,4-dinitrophenylhydrazine-detectable protein products. Carbonylation is irreversible, and carbonylated proteins are marked for proteolysis or can escape degradation and form high molecular weight aggregates, which accumulate with age. Beech (Fagus sylvatica L.) seeds stored under optimal conditions for different periods of time, ranging from 2 to 13 years, were analyzed. Protein carbonylation was examined as a potential cause for the loss of viability of beech seeds, and the characteristic spots of protein carbonyls were identified. Here, we present and discuss the role of carbonylation in the proteome of beech seeds that contribute to the loss of seed viability during natural aging. The long-term storage of beech seeds is intricate because their germination capacity decreases with age and is negatively correlated with the level of protein carbonyls that accumulate in the seeds. We establish that protein synthesis, folding and degradation
\end{abstract}

Communicated by F. Canovas.

Electronic supplementary material The online version of this article (doi:10.1007/s00468-013-0967-9) contains supplementary material, which is available to authorized users.

E. M. Kalemba $(\bowtie) \cdot$ S. Pukacka

Institute of Dendrology, Polish Academy of Sciences,

Parkowa 5, 62-035 Kórnik, Poland

e-mail: kalemba@man.poznan.pl are the most affected biochemical traits in long-term stored beech seeds. In addition, we suggest that proteins associated with the stress response may have contributed to the lowered viability of beech seeds, especially the desiccation toleranceassociated proteins that include T-complex protein 1 and the universal stress protein (USP)-like protein, which is identified as carbonylated for first time here.

Keywords Seeds $\cdot$ Long-term storage $\cdot$ Beech $\cdot$ Protein carbonylation · Aging

\section{Introduction}

Carbonylation is a chemical reaction that produces organic carbonyl compounds containing the $\mathrm{C}=\mathrm{O}$ functional group such as aldehydes and ketones. In proteins, the reaction involves several steps and is due to oxidative stress (Grune et al. 2013). Carbonyl derivatives are produced directly in protein side chains as a result of amino acid oxidation (primarily Pro, Arg, Lys, and Thr) but also by protein fragmentation, and protein aggregation and indirectly by lipid peroxidation (Dalle-Donne et al. 2003; Møller et al. 2011; Grune et al. 2013). The main cause of protein carbonyl generation is reactive oxygen species (ROS) action. ROS react directly either with the protein or with sugars and lipids, which generate reactive carbonyl species (RCS) that react with proteins (Grune et al. 2013). The accumulation of oxidatively modified proteins is widely observed in aged animal tissues and is related to neurodegenerative human diseases (Dalle-Donne et al. 2003). Carbonylation can reduce or totally abrogate the catalytic functions of targeted proteins (Nyström 2005). Carbonylated proteins are subjected to proteasome-dependent degradation or form aggregates (high molecular weight arrangements of 
damaged or unfolded highly carbonylated proteins) (Grune et al. 2013). In addition, the extended accumulation of protein carbonyls can occur while proteasome activity can be inhibited by aggregates (Dalle-Donne et al. 2003; Grune et al. 2013). Conversely, the stability of carbonyls stability favors detection. The reagent 2,4-dinitrophenylhydrazine (DNPH) reacts with the aldehyde or ketone carbonyl group and forms hydrazone derivatives (DNP), thus enabling spectrophotometric or antibody detection (Levine et al. 1994; Reznick and Packer 1994).

In seeds, ROS are produced during important developmental phases, such as maturation, desiccation, germination and aging. ROS function as signaling molecules in response to pathogen attack, abiotic stress tolerance, somatic embryogenesis, programmed cell death, root tropism (Bailly 2004) and during dormancy release (Oracz et al. 2007; Bailly et al. 2008). ROS can be produced by non-enzymatic or enzymatic processes depending on the seed moisture content (MC) (Bailly 2004; Bailly et al. 2008), and ROS overproduction is undesired in seeds. Following ROS actions as signal molecules, the concept of "oxidative window for germination" defined the ROS level limits that can guide a seed to germination (Bailly et al. 2008). Pukacka and Ratajczak (2005) proposed that ROS accumulation was related to the loss of vitality of stored beech seeds. The loss of germination capacity and vitality was correlated with an increase in the concentration of hydrogen peroxide $\left(\mathrm{H}_{2} \mathrm{O}_{2}\right)$ and the superoxide anion $\left(\mathrm{O}_{2}{ }^{-}\right)$, especially in seeds stored under temperature and humidity conditions that were higher than optimal. Although the dry seed tissue metabolism is shut down, the mobility of molecules is reduced or impossible due to very low water content and the high probability of glass matrix structure formation. Longer storage time also correlates with higher accumulated ROS levels; membrane lipid autoxidation is thus suggested as the main source of the accumulated ROS (McDonald 1999). Pukacka and Ratajczak (2007) demonstrated that in beech seeds stored for 10 years at optimal conditions $\left(-10{ }^{\circ} \mathrm{C}, 8-10 \%\right.$ moisture content), the levels of $\mathrm{O}_{2}{ }^{-}, \mathrm{H}_{2} \mathrm{O}_{2}$ and lipid hydroperoxides were highly correlated with the loss of germination capacity. The impact of protein oxidation on seeds (El-Maarouf-Bouteau et al. 2013) and carbonylation on plant physiology (Grune et al. 2013) was recently reviewed. Protein carbonyls seem to play roles in dormancy release and germination, as many proteins were carbonylated in Arabidopsis thaliana seeds during germination and these seeds were then successfully transformed into highly vigorous seedlings and young plants (Job et al. 2005). For that reason, carbonylation is suspected to be a modification associated with several regulatory mechanisms; however, there is, as yet, no known decarbonylation reaction (Wong et al. 2010). Specific enzymes associated with the regulation of the germination process can be carbonylated (Bailly et al. 2008). During dormancy release of sunflower seeds chaperone proteins were found to be carbonylated (Oracz et al. 2007). The carbonylation of heat shock proteins was most likely the result of an oxidative stress associated with maturation seed desiccation. Job et al. (2005) determined that storage proteins were carbonylated in mature, dry A. thaliana seeds. Storage protein carbonyls can complicate or disturb their mobilization during the germination process due to the resistance of protein carbonyls to proteolysis (Grune et al. 2013); conversely, carbonylation can protect them from spontaneous hydrolysis until the start of germination (Job et al. 2005). Consequently, carbonylation would be an element of a signal transduction pathway initiated by ROS that participates in the regulation of different cellular processes and mechanisms. Oracz et al. (2007) showed that protein oxidation occurs during after-ripening and Müller et al. (2007) demonstrated that Arabidopsis atrbohB mutant exibited lower superoxide production during the afterripening period and consequently decrease of the protein oxidation. Thus, identification of carbonylated proteins is helpful to understand the role of this modification in protein function and in cell, tissue, organ and wholeorganism responses. The carbonylation of a key glycolysis enzyme, enolase, was detected in dry A. thaliana seeds, and the carbonyl modification may contribute to a decreased rate of metabolism and ATP production during seed storage (Job et al. 2005).

An analysis of aging performed in seeds of $A$. thaliana (Rajjou et al. 2008) and Thuja plicata (Terskikh et al. 2008) established the association of protein carbonyls with a decrease in germination capacity. Protein carbonylation has never been analyzed in woody plant seeds that have to be stored in seed banks as resources for reforestation, especially seeds of beech (Fagus sylvatica L.), which is the main forest species in Europe. So far, the proteome of beech seeds was analyzed only in the aspect of mechanisms of dormancy breaking (Pawłowski 2007). ROS accumulation and an insufficient action of antioxidant systems were detected in long-term stored beech seeds that showed a lowered germination capacity (Pukacka and Ratajczak 2007). Because ROS are the main cause of RCS creation, it was necessary to investigate whether protein carbonylation is one of the factors that affect the germination rate in beech seeds during long-term storage. Our results suggest that there is a link between the vitality of beech seeds and the level of protein carbonyls. Therefore, extended analyses were performed, including the identification of carbonylated proteins that were suspected to be related to the loss of germination capacity. 
Table 1 Description of seed material

\begin{tabular}{lll}
\hline Year of seedlots collection & City/superintendence & Years of storage \\
\hline 2009 & Kórnik and Waligród & 2 \\
2006 & Dynów and Kórnik & 5 \\
2003 & Kórnik & 8 \\
2000 & Rymanów & 11 \\
1998 & Bierzwnik & 13
\end{tabular}

The origin and cropping year are given for each analyzed seedlot. The years of storage were calculated when the germination test was conducted

\section{Methods}

Material preparation

Seeds of common beech (F. sylvatica L.) were obtained from forest seed banks in Białogard and Dukla (Bierzwnik, Dynów, Rymanów, Baligród) or were collected in Kórnik Arboretum (Poland); all seeds were collected in good cropping years, beginning in 1998 (Table 1). From the seed banks, seeds were transported to our laboratory in a cooling box and were then stored with pericarps at $-10{ }^{\circ} \mathrm{C}$ in plastic boxes. The seed water content reached $8-9 \%$ (fresh weight basis). Seeds that were gathered in the Kórnik Arboretum were cleaned and dried to 7-10\% moisture content and were stored in closed plastic boxes at $-10{ }^{\circ} \mathrm{C}$. All seedlots were stored at the optimal conditions provided for beech seeds (León-Lobos and Ellis 2002; Pukacka et al. 2003).

\section{Germination test}

A germination test was performed on four samples of 50 seeds each. Dry seeds were hydrated at $100 \%$ relative humidity (RH) for $24 \mathrm{~h}$. Fully imbibed seeds were placed between moist rolled paper towels in separate boxes and incubated at $3{ }^{\circ} \mathrm{C}$. Stratification was conducted for 26 weeks. A seed was scored as germinated when the radicle protruded $5 \mathrm{~mm}$. Germination counts were made every week, and the germinated seeds were removed (ISTA 1999).

\section{Protein extraction}

After removing the seed coats, embryonic axes and cotyledons were separated and ground to a powder in liquid nitrogen. The dried powder was homogenized at $4{ }^{\circ} \mathrm{C}$ in extraction buffer $(20 \mathrm{mM}$ potassium phosphate $\mathrm{pH} 7.5$, containing $1 \%$ antiprotease cocktail containing AEBSF, bestatin, pepstatin A, E-64, leupeptin and 1,10-phenanthroline $(1 \mu \mathrm{l} / \mathrm{mL}), 60 \mathrm{U} / \mathrm{mL}$ of DNAse $\mathrm{I}, 6 \mathrm{U} / \mathrm{mL}$ of
RNAse A and $20 \mathrm{mM}$ DTT) and then centrifuged at $4{ }^{\circ} \mathrm{C}$ at $20,000 \times g$, and the supernatant was collected. Protein concentration in extracts intended for carbonyl group measurement and 1D electrophoresis was measured according to the Bradford (1976) method using BSA as a standard. Proteins intended for 2D electrophoresis (2DE) were precipitated with acetone and then solubilized in buffer containing $7 \mathrm{M}$ urea, $2 \mathrm{M}$ thiourea, $40 \mathrm{mM}$ DTT, $0.5 \%$ carrier ampholytes, and $4 \%$ CHAPS. Protein concentration was measured using the 2D Quant Kit (GE Healthcare).

\section{Protein carbonylation}

The level of carbonylated proteins was measured spectrophotometrically according to the Reznik and Packer method (Reznick and Packer 1994) involving the derivatization of the carbonyl groups with 2,4-dinitrophenylhydrazine (DNPH), which leads to the formation of a stable dinitrophenyl hydrazone product (DNP) with a maximum absorbance at the $360-380 \mathrm{~nm}$ wavelength. The absorbance was read against the blank of each sample using $1-\mathrm{cm}$ cuvettes. The calculation of protein carbonyls was based on the fact that the molar extinction coefficient $(\varepsilon)$ for DNPH at $375 \mathrm{~nm}$ is $22,000 / \mathrm{M} / \mathrm{cm}$. The data are presented in $\mathrm{nmol} / \mathrm{mg}$ protein units.

\section{Electrophoresis}

1D electrophoresis was performed according to the Laemmli (1970) method using $12 \%$ polyacrylamide mini-gels and the Mini-PROTEAN ${ }^{\circledR}$ Tetra Cell (Bio-Rad). $12 \mu \mathrm{g}$ of protein extract were loaded onto a 1D gel and protein molecular mass was estimated according to the Broad Spectra Prestained Protein Molecular Weight Marker (Fermentas). Isoelectrofocusing was conducted using 7-cm ready gel strips $\mathrm{pH}$ 4-7 and the Multiphor II Electrophoresis System (GE Healthcare). The electrophoresis results were analyzed using the ImageMaster 2D Platinum 7.0 (GE Healthcare) program. 2DE gels were stained with silver (Sinha et al. 2001).

\section{Western blot}

Fractionated proteins were transferred from gel onto a polyvinylidene fluoride membrane (Immobilon-P, Millipore) at $350 \mathrm{~mA}$ for $1 \mathrm{~h}$ using the Mini Trans-Blot ${ }^{\circledR}$ Cell (Bio-Rad). Following transfer, the membranes were treated in one of two different ways. First, membranes were blocked with $1 \%$ BSA and incubated with antibodies delivered with the OxyBlot ${ }^{\mathrm{TM}}$ Protein Oxidation Detection Kit (Millipore), and DNPs were visualized using the ECL Kit (GE Healthcare). The results were 


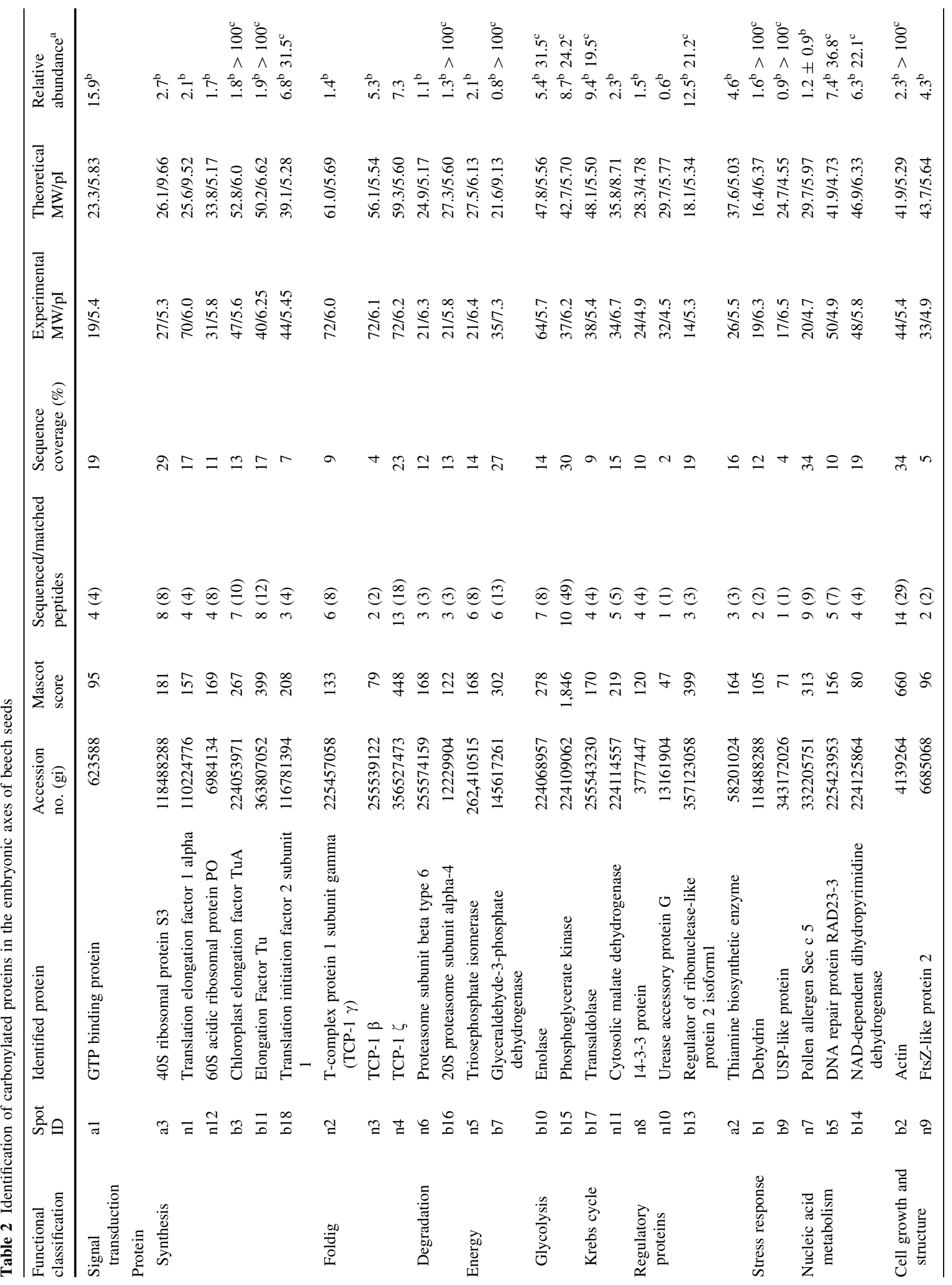




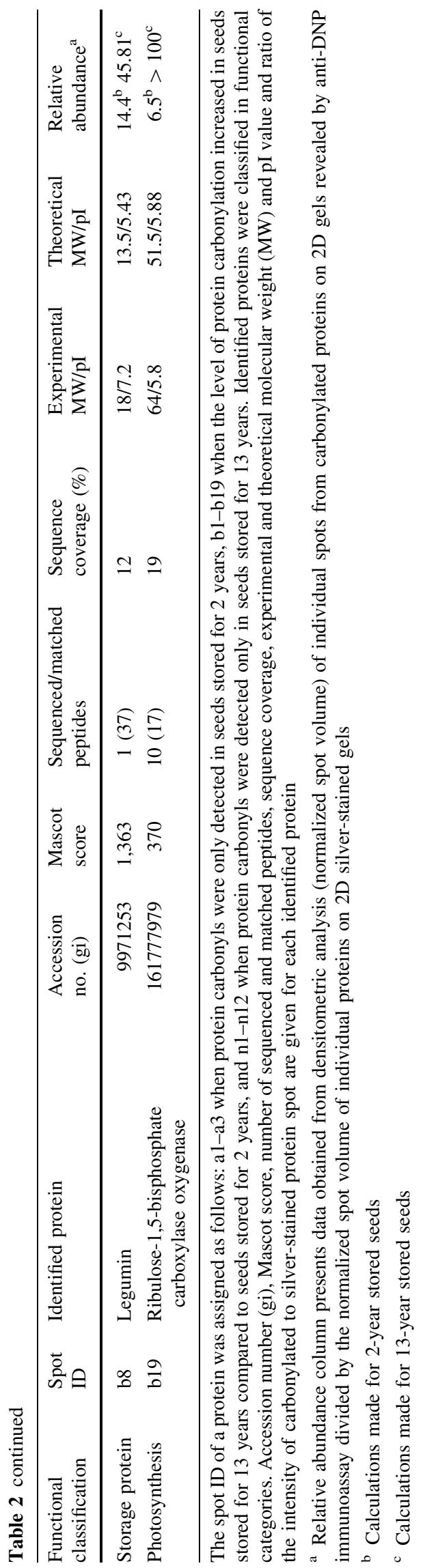

analyzed using the ImageMaster 2D Platinum 7.0 software. Selected spots were excised automatically using the Ettan Spot Picker (GE Healthcare). For each analysis, statistical data showed a high level of reproducibility between the normalized spot volumes of OxyBlots produced in triplicate from independent protein extractions. Specific spots of protein carbonyls were described as showing variations when their volumes increased by at least $30 \%$. Second, membranes were blocked with $5 \%$ skimmed milk and incubated with primary anti-USP antibody (Abcam) and secondary anti-rabbit antibody conjugated to alkaline phosphatase. USP-like protein detection was visualized via a reaction with an alkaline phosphate substrate (5-bromo-4-chloro-3-indolyl phosphate/nitro blue tetrazolium).

\section{Mass spectrometry}

Selected protein spots were excised automatically using the Ettan Spot Picker (GE Healthcare). The gel pieces were subjected to the standard in-gel digestion procedure, during which proteins were reduced with $100 \mathrm{mM}$ DDT (for $30 \mathrm{~min}$ at $50{ }^{\circ} \mathrm{C}$ ), alkylated with iodoacetamide (45 min in darkroom at room temperature) and digested overnight with trypsin (sequencing Grade Modified Trypsin-Promega V5111). The resulting peptides were eluted from the gel with $0.1 \%$ TFA, $2 \%$ ACN. Peptide mixtures were analyzed by liquid chromatography (nanoACQUITY UPLC, Waters) coupled to LTQ Orbitrap Velos hybrid FT mass spectrometer (Thermo). An extract was applied to a RP-18 precolumn (LC Packings) using water containing $0.1 \%$ TFA as the mobile phase and were then transferred to a nano-HPLC RP-18 column (nanoACQUITY UPLC BEHC18Waters 186003545) using an acetonitrile gradient $(0-60 \% \mathrm{ACN}$ in $30 \mathrm{~min})$ in the presence of $0.05 \%$ formic acid with a flow rate of $150 \mathrm{nl} / \mathrm{min}$. The column outlet was directly coupled to an ion source of LTQ-FTMS working in the regime of data-dependent MS to MS/ MS switch. A blank run ensuring a lack of cross contamination from previous samples preceded each analysis.

Acquired raw data were processed by Mascot Distiller, followed by Mascot Search (Matrix Science, London, UK, locally installed http://proteom.pl/mascot) against the NCBI non-redundant database. The search parameters for precursor and product ions mass tolerance were $\pm 40 \mathrm{ppm}$ and $\pm 0.8 \mathrm{Da}$, respectively, with an allowance made for one missed semi-trypsin-fixed modification of cysteine through carbamidomethylation and a variable modification through lysine carbamidomethylation and methionine oxidation. 


\section{Results}

Seed germination

The germination test was conducted in all seven seedlots, and significant differences were observed. Seeds that have been stored for 2 years had a $100 \pm 0 \%$ germination capacity (Table 1). For seeds stored for longer time periods, the germination capacity decreased. Seeds that had been stored for 5 and 8 years had similar germination capacities of $84 \pm 1.4 \%$ and $82 \pm 2 \%$, respectively. Seeds stored for 11 years had a germination capacity that was reduced to $66 \pm 3.8 \%$. The lowest germination capacity of $28 \pm 2.8 \%$ was noted for seeds stored for the longest time period. To analyze seed germination dynamics, germination curves were compared (Fig. 1).

Quantity of protein carbonyls

The amount of carbonylated proteins measured separately in embryonic axes and cotyledons or in whole seeds gave similar results (results not shown). Whole seeds were used in this study, and the values were presented in nmol of protein carbonyls per $\mathrm{mg}$ of protein (nmol/mg). The smallest amount of protein carbonyls was detected in extracts from seeds that had been stored for the shortest time $(2.98 \mathrm{nmol} / \mathrm{mg})$. In seeds that had been stored for 5,8 and 11 years, the amount of protein carbonyls gradually increased and was on average $3.9-4.6 \mathrm{nmol} / \mathrm{mg}$. In seeds that had been stored for 13 years, the amount of protein carbonyls increased notably and reached a value of $8.3 \mathrm{nmol} / \mathrm{mg}$ (Fig. 2a). Summarizing the results compared to seeds stored for 2 years, seeds stored for 5-11 years had 1.5-2 times the amount of protein carbonyls and seeds stored for 13 years had 2.5-4 times the amount of protein carbonyls. Carbonyl proteins were detected in the embryonic axes of beech seeds after 1D SDS-PAGE (Fig. 2b). The results were consistent with earlier quantitative analyses (Fig. 2a) and confirmed that older seeds contained more protein carbonyls. Two seedlots that differed dramatically in germination capacity and the amount of protein carbonyls were led to germinate; during this experiment, seeds were collected after $24 \mathrm{~h}$ of imbibitions (0 time), after 3, 6 and 9 weeks of stratification and after 12 weeks as germinated seeds. Differences in the amounts of protein carbonyls between seeds stored for 2 and 13 years were detected at the initial step in dry seeds, after imbibition, and during all times of stratification, and these differences remained until the seeds germinated (Fig. 2c). However, the pattern of changes during stratification was identical for both seedlots. One seedlot that had been stored for the shortest time (originated from Kórnik Arboretum) was also analyzed before storage (cropping year 2009).

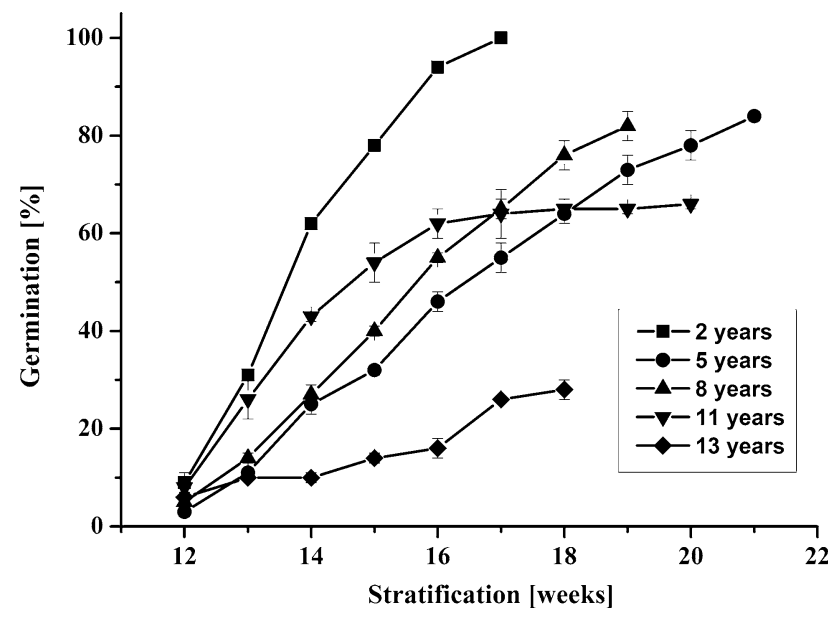

Fig. 1 Germination kinetics of beech (Fagus sylvatica L.) seeds that had been stored for 2, 5, 8, 11 and 13 years. Germination curves were calculated from data obtained from germinated seeds counted every week beginning at the 12th week and ending at the 17-21st week of cold stratification. Mean $\pm \mathrm{SD}, n=3$

During seed maturation time, i.e., between 11 and 20 weeks after flowering (WAF), the amount of protein carbonyls was tested in embryonic axes in 1- to 1.5 -week intervals (Fig. 2d). The highest amount, over $6 \mathrm{nmol} / \mathrm{mg}$, was detected at $16 \mathrm{WAF}$, which is the time when beech seeds acquire desiccation tolerance. After the phenomenon, the amount of protein carbonyl decreased. There were no significant differences between the amounts of protein carbonyls before (Fig. 2d) and after the 2-year storage time (Fig. 2a).

The correlation coefficient $(r)$ between the percentage of seed germination capacity and the level of protein carbonyls was calculated for whole beech seeds stored for 2, 5, 8, 11 and 13 years (Fig. 3). The correlation coefficient was significant $(r=-0.93, p=0.02)$, indicating that there was a relationship between the level of protein carbonyls and germination capacity in beech seeds (i.e., seeds that contained more protein carbonyls had a worse germination capacity).

Qualitative analyses of protein carbonyls

It was impossible to find specific differences among the analyzed seedlots after 1D SDS-PAGE (Fig. 2b); therefore, $2 \mathrm{DE}$ was necessary to identify the proteins that contained carbonyl groups. Because the seeds that had been stored for 2 and 13 years were the most dissimilar in germination capacity and protein carbonyl level, these two seedlots were analyzed with 2DE and the OxyBlot $^{\mathrm{TM}}$ Protein Oxidation Detection Kit (Millipore). For each experiment, the results were obtained with different times of exposure to chemiluminescence to detect all of the proteins that contained carbonyl groups. To control 

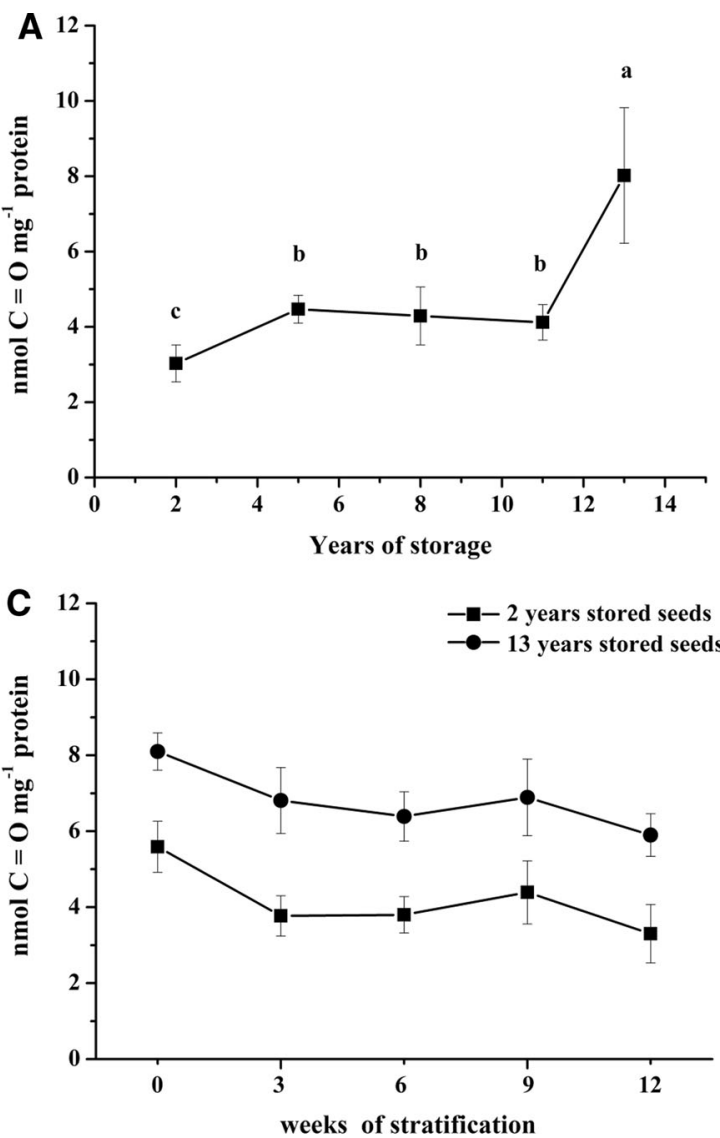

Fig. 2 The amount of protein carbonyls detected in beech (F. sylvatica L.) seeds. a Protein carbonyls detected in whole beech seeds that had been stored for 2-13 years. b Protein carbonyls reported in the embryonic axes of beech seeds. Lanes 1-5 correspond to seeds that had been stored for 2, 5, 8, 11 and 13 years, respectively. $10 \mu \mathrm{g}$ was loaded on each lane and Broad Spectra Prestained Protein Molecular Weight Marker (M) was used. Protein carbonyls were detected with OxyBlot $^{\mathrm{TM}}$ Protein Oxidation Detection Kit. Western blot demonstrates results obtained in three independent gels per sample. $\mathbf{c}$ Protein carbonyls detected in the embryonic axes of beech seeds stored for 2

for potential exposure variation, gels representing the proteins obtained from embryonic axes from seeds stored for 2 and 13 years were transferred onto one membrane and analyzed. The experiments were repeated three times on different extracts and analyzed in the ImageMaster 2D Platinum 7.0 program (GE Healthcare). Analyses with different exposure times were necessary because some protein spots gave extremely strong signals and it was not possible to separate the signals without the spot propagation option from results obtained after short exposure. Approximately 250 spots referring to protein carbonyls in the embryonic axes of the oldest seeds were reported (Fig. 4). Unexpectedly, a large amount of protein carbonyls were detected in the embryonic axes of seeds that had been characterized with $100 \%$ germination capacity (Fig. 4a). Therefore, to find differences in
B
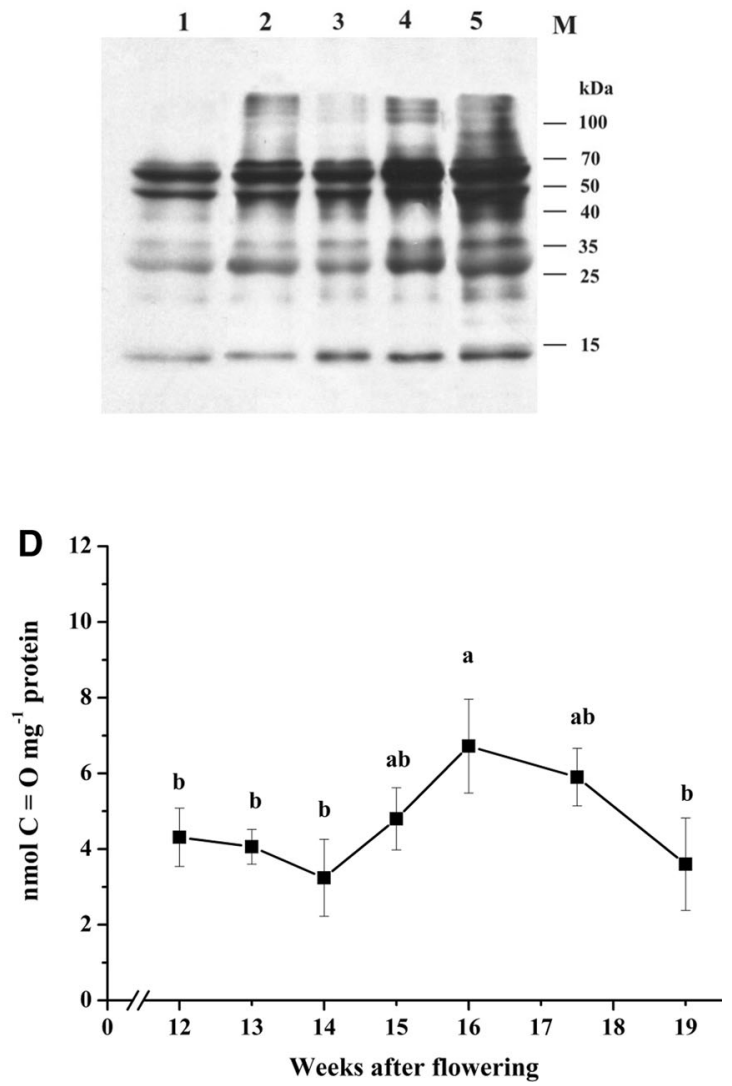

and 13 years that were allowed to germinate. Analyses were performed during stratification (0-12th week) and started in imbibed seeds ( 0 weeks), and ended in germinated seeds (12th week). The values of the detected protein carbonyls were different between seedlots stored for 2 and 13 years at each analyzed point. Statistically significant differences are indicated with different letters. Data are mean $\pm \mathrm{SD}$ of three independent replications, $n=3$. d Protein carbonyls detected in the embryonic axes of beech seeds from the 2009 cropping year and measured during seed maturation between the 11 th and 20th week after flowering

the two chosen seedlots, spots were quantified statistically in ImageMaster 2D Platinum 7.0, and three groups of proteins were chosen for identification: (1st) proteins observed only in seeds stored for 2 years, (2nd) newly carbonylated proteins in seeds stored for 13 years, (3rd) proteins with a signal increased by $30-100 \%$ in seeds stored for 13 years compared to seeds stored for 2 years. Oxy-blot maps of spots were compared automatically with silver-stained 2DE gels using ImageMaster 2D Platinum 7.0 (Supplementary data Fig. S1), and three selected spot-sets were identified in a gel and excised for identification (Table 2). As expected after the quantitative analyses (Fig. 2c), the $28 \%$ pool of seeds stored for 13 years that initiated the germination process contained higher amounts of protein carbonyls (Fig. 4d) compared to seeds stored for 2 years (Fig. 4c). 


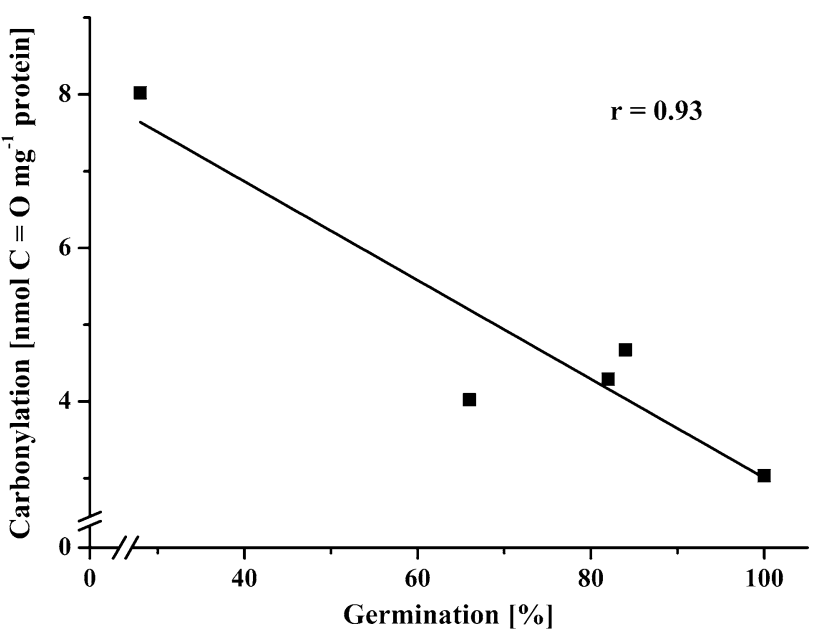

Fig. 3 Correlation ( $r$ ) between the germination capacity (\%) (Fig. 1) and the level of protein carbonyls (Fig. 2a) calculated for whole beech (Fagus sylvatica L.) seeds stored for 2, 5, 8, 11 and 13 years

The identified proteins were functionally analyzed (Table 2). About $37 \%$ of the identified proteins were associated with protein synthesis, protein folding or proteolysis, $21 \%$ with energy production, $10 \%$ with metabolism pathways, others were regulatory proteins, stress response proteins, storage proteins, proteins linked with cell growth and signal transduction (Table 2).

\section{Proteins containing a USP domain}

Anti-Universal Stress Protein (USP) antibody (Abcam) was used to identify the proteins that contained a USP domain in stored beech seeds. Two proteins were detected with molecular masses of $29 \mathrm{kDa}$ (a classical USP protein) and $45 \mathrm{kDa}$ (a eukaryotic serine/threonine kinase with $N$-terminal domain homology to USP proteins) (Fig. 5a). The level of the $29 \mathrm{kDa}$ USP-like protein was only higher in seeds stored for 5 years. Remaining seedlots were found to contain similar USPlike protein levels. In contrast to the levels of $29 \mathrm{kDa}$ USP-like protein detected in embryonic axes of dry seeds (Fig. 5a), after $24 \mathrm{~h}$ of imbibition seeds stored for 13 years contained reduced USP-like protein levels when compared to seeds stored for 2 years (Fig. 5b). The level of the $45 \mathrm{kDa}$ Ser/Thr kinase with a USP domain was the highest in the youngest seeds and decreased as the seeds aged. Protein spot b9 was identified as a USP-like protein in embryonic axes (Fig. 5c). A digital comparison of the spot revealed that b9 protein carbonylation in seeds stored for 13 years increased in intensity $(60 \%$ increase), spot area (151\% increase), spot volume (308\% increase), and percent volume (286\% increase) relative to seeds stored for 2 years.

\section{Discussion}

Germination capacity of long-term stored seeds

Beech (F. sylvatica L.) seeds present orthodox behavior when they acquire desiccation tolerance during seed development (Kalemba et al. 2009) and form a glassy matrix in the dry state (Pukacka et al. 2003). However, during long-term storage, beech seeds present intermediate behavior because the seeds lose viability faster than other orthodox seeds (Pukacka and Ratajczak 2007). The results of seed germination capacity (Fig. 1) are in perfect agreement with the results obtained previously with beech seeds originated from different provenances (Pukacka and Ratajczak 2007). Similarly, seeds stored for 2, 5, 7 and 10 years had germination capacities of 97, 87, 68 and $20 \%$, respectively. This indicates that for more than 7 years seed storage under optimal conditions cannot preserve seed vitality and that the maintenance of low temperature and low moisture content is not able to stop processes leading to dramatic decreases in seed vitality. We tested seeds that had been stored from 2 to 13 years and a significant negative correlation was observed between germination capacity and protein carbonyls content (Fig. 3), consistent with the idea that there is a link between the protein carbonylation level and the germination capacity of beech seeds. The increasing amount of protein carbonyls in stored seeds (Fig. 2a) was consistent with the carbonyl levels detected in embryonic axes after 1D SDS-PAGE of soluble protein extracts (Fig. 2b).

\section{Identification of carbonylated proteins}

The role of oxidative carbonylation in protein quality control and senescence is important (Nyström 2005), and research focusing in this area can help address the downstream implications of this phenomenon. In this study, selected carbonylated proteins extracted from the embryonic axes of beech seeds were identified by mass spectrometry. Because seeds stored for 2 years were unaffected in germination capacity (Fig. 1), it can be hypothesized that proteins identified in the first group (Table 2 a1-a3) might have regulatory functions and participate in unknown carbonylation-mediated signal transduction pathways involving the action of plant GTPases (Verma et al. 1994; $\mathrm{Xu}$ 2012) and modulators of enzymes since carbonylation as a spontaneous, random and non-specific modification seems to be less probable (Maisonneuve et al. 2009).

Protein carbonyls specific for the oldest seeds (Table 2 n1-n12) that had poor germination capacity (Fig. 1) contained three subunits $(\gamma, \beta, \zeta)$ of T-complex protein 1 

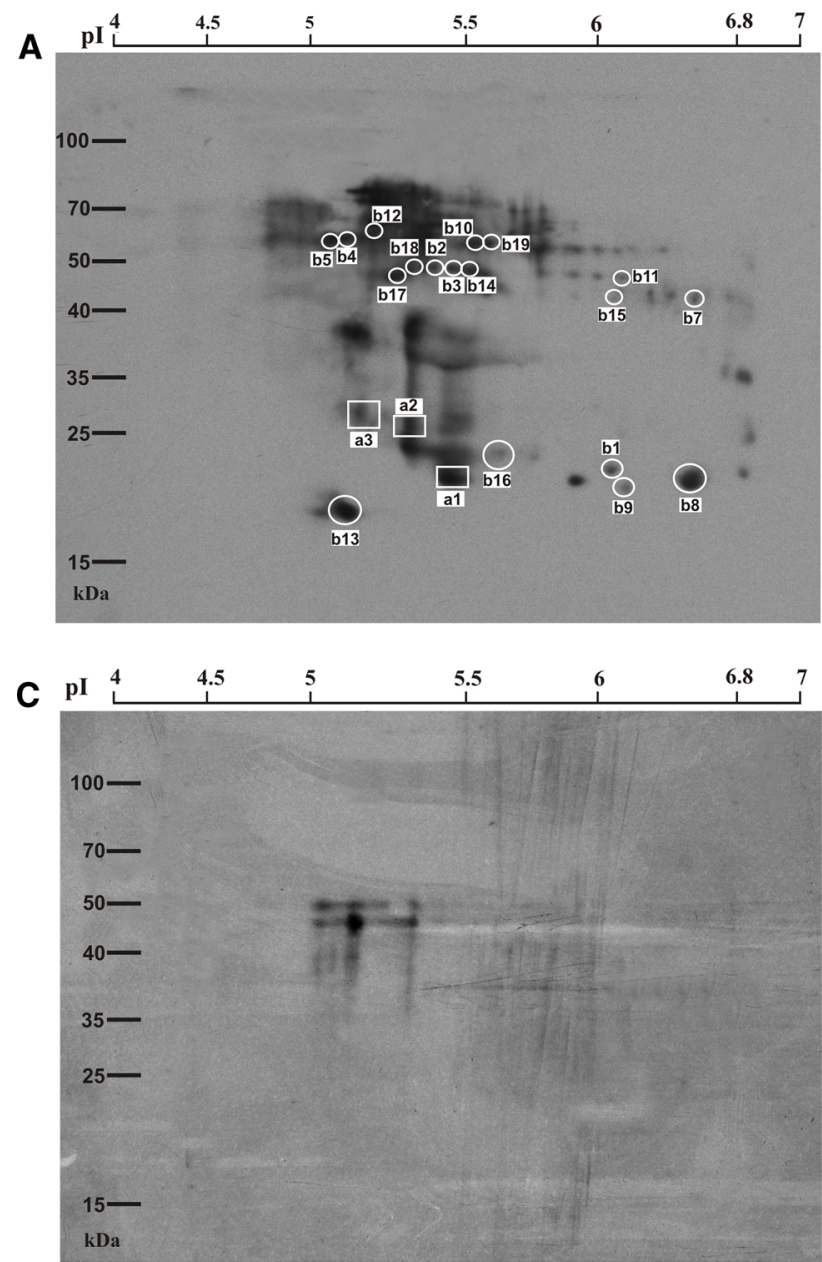

Fig. 4 Carbonylated proteins detected in embryonic axes of beech seeds that have been stored for 2 years (a) upon 13 years (b). Protein spots organized in 1st $(a)$, 2nd $(n)$, and 3rd $(b)$ groups are annotated with a number following the group letter. Proteins extracted from embryonic axes were isoelectrofocused using a 4-7 $\mathrm{pH}$ range. Carbonylated proteins were also reported in embryonic axes of

(TCP-1) (Fig. 4; n2, n3, n4 spots). Recently, TCP-1 was suggested to be one of the seven most important proteins associated with the loss of desiccation tolerance (Wang et al. 2012). The main activities of TCP-1 are folding of a broad range of proteins, including actin and tubulin, and restoring protein native states (Cong et al. 2010) via the ability of the $\gamma, \zeta$ and $\theta$ subunits to bind major nonnative substrates and five other that strongly hydrolyze ATP (Kalisman et al. 2013). Consequently, the affected protein metabolism due to the reduced action of TCP-1 and other translation-related proteins in long-term stored beech seeds is a potential explanation for the decreased seed viability. It can be speculated that carbonylation of several subunits might contribute to the altered TCP-1 function because this protein is ordered spatially as a 16-subunit molecule and because interactions between subunits are essential for the proper arrangement and action of the protein (Cong et al.
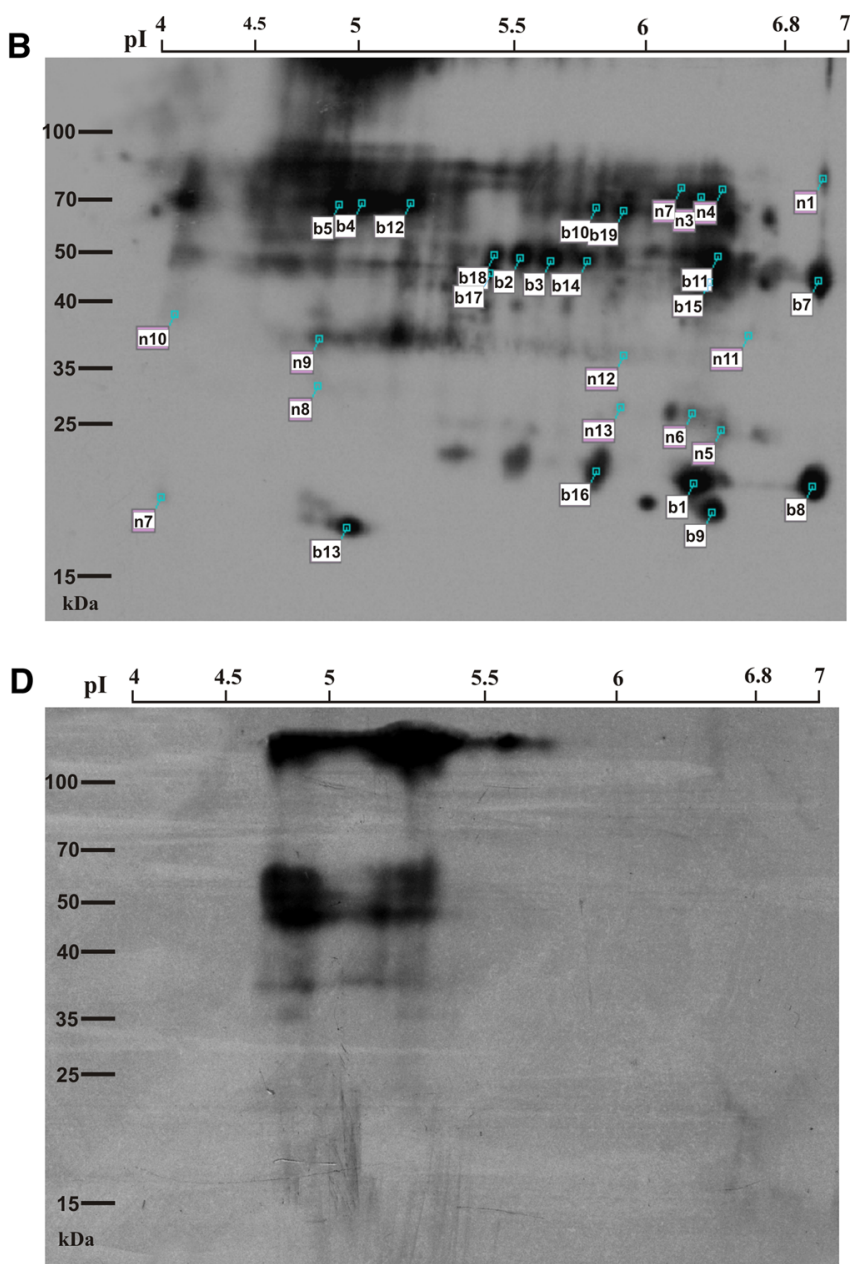

germinating seeds that had been stored for 2 years $(\mathbf{c})$ or 13 years $(\mathbf{d})$. $60 \mu \mathrm{g}$ were loaded on each gel strip and Broad Spectra Prestained Protein Molecular Weight Marker (M) was used. Protein carbonyls were detected with OxyBlot ${ }^{\mathrm{TM}}$ Protein Oxidation Detection Kit. Western blot demonstrates results obtained in three independent gels per sample

2010). The majority of the identified carbonylated proteins were associated with protein metabolism, including protein synthesis, protein folding and protein degradation (Table 2). Therefore, protein synthesis and native conformation preservation are likely to be the most affected biochemical processes in the embryonic axes of stored beech seeds. The proteins involved in translation, which include elongation factors (Table 2) have been found to be targets of oxidation (Katz and Orellana 2012). Oxidative modifications of the proteins and mRNA involved in the translation process have implications on the seed germination process because seed dormancy alleviation appears to require both selective mRNA oxidation and protein carbonylation (El-Maarouf-Bouteau et al. 2013).

In the present study, $\alpha 4$ and $\beta 6$ proteasome subunits were identified as proteins with increased levels of carbonylation after long-term storage (Table 2). In the spatial 


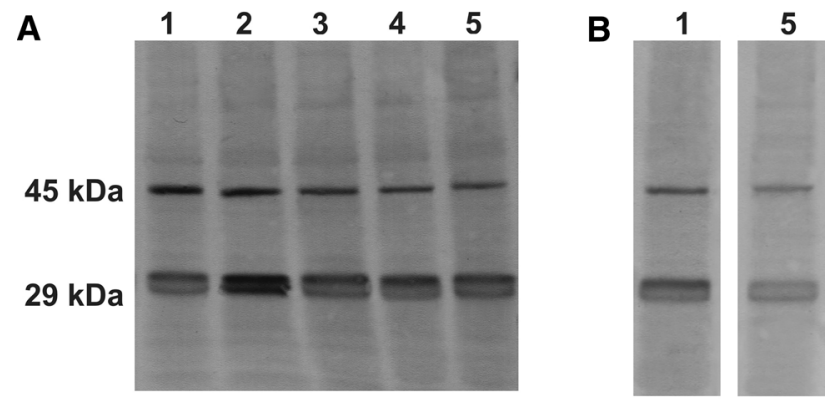

C 1

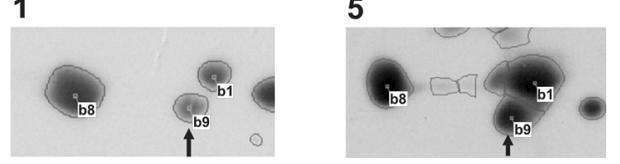

Fig. 5 Western blot detection of USP-like protein in embryonic axes of beech seeds. a The 29 and $45 \mathrm{kDa}$ USP-like proteins. Lanes 1-5 correspond to seeds that had been stored for 2, 5, 8, 11 and 13 years, respectively. b Lanes 1 and 5 show seeds that had been stored for 2 and 13 years, respectively, and were imbibed for $24 \mathrm{~h} .30 \mu \mathrm{g}$ was loaded on each lane and Broad Spectra Prestained Protein Molecular Weight Marker (M) was used to calculate the molecular weight of proteins detected with the Anti-Universal Stress Protein antibody (1/ 500 dilution). Western blot demonstrates results obtained in three independent gels per sample. c Protein spot b9 (pointed with an arrow) that corresponds to the carbonylation level of the $29 \mathrm{kDa}$ USP-like protein reported in seeds that had been stored for 2 years (1) and 13 years (5). Detection of protein carbonyls was performed with the use of OxyBlot ${ }^{\mathrm{TM}}$ Protein Oxidation Detection Kit

structure, $\alpha 4$ and $\beta 6$, are located directly next to the catalytic $\beta 5$ subunit; therefore, potentially the chymotrypsinlike activity (Pickart and VanDemark 2000) and cell homeostasis (Pickering et al. 2010) could be affected after 13 years of storage because the protein carbonyl level was higher in embryonic axes in the dry state, after imbibition, during dormancy release and during germination compared to seeds stored for 2 years (Figs. 2b, 4). These results might help explain why only $28 \%$ of the seeds germinated in this seedlot (Fig. 1). Carbonylated proteins are degraded through the action of the 20S proteasome in the cytosol (Nyström 2005) and other proteases including mitochondrial and plastidial Lon and FtsH proteases (Lounifi et al. 2013). Proteasome-dependent protein degradation is also dependent on the proper action of the ubiquitin ( $\mathrm{Ub}$ ) receptor protein RAD23 (Table 2) (Wade and Auble 2010) that delivers the Ub-substrates to the $26 \mathrm{~S}$ proteasome (Farmer et al. 2010). Disturbance of the cell division process may be the one of the causes of seed germination defects since FtsZ, the plastid division protein (Smith et al. 2011) that blocks cell division in cells containing damaged DNA (Mukherjee and Lutkenhaus 1998), and RAD23 and ribosomal PO protein (Table 2) involved in DNA repair process (Yacoub et al. 1996) were found to be carbonylated.
In seeds, the 14-3-3 (Table 2) appears to be ABAdependent protein (Testerink et al. 1999) involved in the stress signal transduction pathway because this protein is phosphorylated by SnRK.8, an important kinase for drought resistance (Denison et al. 2011). Via interactions with phosphorylated proteins 14-3-3 modulates their function and consequently regulates transport through ion channels, virulence-mediated programmed cell death, ROS production as a defense mechanism and microtubule cell arrangement (Denison et al. 2011). Therefore, in long-term stored seeds, many biochemical traits might be modified, thus contributing to the no-germination seed phenotype. In Arabidopsis seeds, Late Embryogenesis Abundant (LEA) proteins were more oxidized in deteriorated seeds than in control seeds indicating that proteins of this class contribute to seed vigor (Rajjou et al. 2008). During the long-term storage of beech seeds, the level of the $26 \mathrm{kDa}$ dehydrin was correlated with the loss of germination capacity (Kalemba and Pukacka 2008). In the present study, the carbonylation of low molecular weight dehydrin was discovered, and the carbonylation level increased after longterm storage (Table 2).

Universal stress proteins (USPs) belong to the adenine nucleotide alpha hydrolases-like family of proteins with no ATPase activity and are synthesized after the appearance of different stress factors. Proteins containing a USP domain are critical for the survival of bacteria under stress conditions in vitro and in vivo (Seifart Gomes et al. 2011). In plants, the expression of USP can be induced by dehydration, salinity stress, oxidative stress and ABA. The overexpression of USP can result in increased desiccation tolerance in seedlings, young plants and at later developmental stages (Loukehaich et al. 2012), which indicates that desiccation tolerance-associated USP proteins are critical for stress condition endurance beyond bacteria. Analyses of the appearance of USP-like proteins in dry stored beech seeds (Fig. 5a) established that protein regulation by phosphorylation may additionally be disrupted in long-term stored seeds because the level of a $45 \mathrm{kDa}$ kinase containing a UPS domain decreased as storage time progressed. The increase in the intensity of carbonylation of the $29 \mathrm{kDa}$ USP-like protein (Fig. 5c) is high, considering that this protein level is similar in the embryonic axes of dry seeds stored for 2 and 13 years (Fig. 5a). After imbibition the level has changed (Fig. 5b) and decreased in seeds stored for 13 years suggesting that degradation of protein carbonyls was initiated just after seed rehydration and resulted in reduced USP-like protein level. This finding may support our hypothesis on the loss of desiccation tolerance, especially because TCP-1 was carbonylated only in the oldest seeds (Fig. 4) and also glyceraldehyde-3phosphate dehydrogenase (GAPDHc) (Table 2) was identified to be a desiccation-specific protein in Arabidopsis 
seeds (Gallardo et al. 2002). This hypothesis is in perfect agreement with the conclusion of Wang et al. (2012) that seed desiccation tolerance is related to pathogen defense, protein conformation conservation and cell structure stabilization.

\section{The causes of poor seed vitality}

Several proteins reported as carbonylated, including dehydrin, USP, TCP-1, RAD23-3, and 14-3-3 protein might be potential candidates that contribute to poor beech seed vitality after long-term storage since translational capacity, detoxification efficiency, protective proteins, cell repair and turnover appear to be essential mechanisms for seed vigor (Rajjou et al. 2008; Rajjou and Debeaujon 2008). Because the stress response is evolutionarily well-conserved, similar or identical proteins can undergo stressmediated carbonylation. Therefore, sets of carbonylated proteins (Table 2) were identical with those identified as herbicide-induced (Braconi et al. 2009), and those associated with the apoptotic response to oxidative stress (Magi et al. 2004). Rajjou et al. (2008) demonstrated that Arabidopsis seeds underwent an oxidative stress during aging and the oxidation of proteins certainly entails an alteration of seed survival in the dry state and, subsequently, during their germination. Increasing amounts of protein carbonyls affect the germination capacity of beech seeds (Fig. 3). Comparing the levels of protein carbonyls in dry seeds and during the time of dormancy release up to germination (Fig. 2c), the data suggest that seeds stored for either 2 or 13 years underwent changes in a similar manner. However, significantly greater amounts of protein carbonyls were always observed in seeds stored for 13 years that initiated the germination process. Comparing the proteomes of deteriorated and control Arabidopsis seeds during germination sensu stricto ( $24 \mathrm{~h}$ after imbibition), 11 proteins with decreased abundance were identified, and among them, 8 proteins (60S acidic ribosomal protein $\mathrm{P} 0-\mathrm{C}$, TCP-1- $\theta$, GAPDH, triose phosphate isomerase, phosphoglycerate kinase, LEA, actin7, and 12S seed storage protein) were identical to the proteins identified as carbonylated in beech seeds (Table 2). Among the proteins inhibited for de novo synthesis during germination sensu stricto of deteriorated seeds were proteins carbonylated in beech seeds, such as EF-2, TCP-1- $\theta$, GAPDH, dehydrin, and $12 \mathrm{~S}$ seed storage protein (Rajjou et al. 2008) emphasizing these proteins particularly sensitive to carbonylation under stress conditions.

As opposed to a solely deleterious modification, protein carbonylation may serve as a regulatory mechanism of metabolic pathways (Job et al. 2005). This appears to be the case for glycolytic enzymes (Table 2), which were carbonylated in beech seeds characterized with $100 \%$ germination capacity (Fig. 1) and previously in Arabidopsis (Job et al. 2005; Møller et al. 2007) and sunflower seeds (Oracz et al. 2007) and also legumin (Table 2) emphasizing that carbonylation may protect storage proteins from premature proteolysis (Job et al. 2005) or may act as a trap for ROS (Rajjou and Debeaujon 2008).

Is carbonylation a component of signal transduction pathways?

Carbonylation represented a signaling mechanism for the induction of apoptosis in HL60 cells (Magi et al. 2004). Wong et al. (2010) suggested that ROS produced by $\mathrm{NAD}(\mathrm{P}) \mathrm{H}$ oxidase elicit signal transduction and primary protein carbonylation mediates cell signaling. The ribulose1,5-bisphosphate carboxylase oxygenase (RubisCO) large and small subunits (Muthuramalingam et al. 2013) and malate dehydrogenase (MDH) (Table 2) have been recently identified as proteins sensitive to $\mathrm{H}_{2} \mathrm{O}_{2}$. RubisCO carbonylation (Table 2) was previously detected in Arabidopsis seeds (Rajjou et al. 2008) and in rice and pea chloroplasts; further, this enzyme can also undergo phosphorylation (Reiland et al. 2009) and oxidation-mediated nitrosylation (Møller et al. 2007). In parallel, MDH mitochondrial isoform was detected to be carbonylated in rice and the cytoplasmic isoform was found to be nitrosylated (Møller et al. 2007). Protein carbonylation, nitrosylation and other ROS-mediated posttranslational modifications act in proteome remodeling through stress response and metabolic activity control and cell signaling and communication during various physiological processes in plants (Lounifi et al. 2013) pointing that the interplay between different protein modifications is required. Carbonylation could play a role in the regulation of proteome dynamics (Nyström 2005) promoting degradation of oxidized proteins and initiation of signaling pathway mediated by peptides resulting from protein degradation that might act as secondary ROS messengers (Møller and Sweetlove 2010). Cellular signaling stress pathways induced by ROS and reactive nitrogen species could be mediated by two competitive protein modifications carbonylation and nitrosylation (Lounifi et al. 2013) because nitrosylation can modify the spatial protein structure preventing its carbonylation (Tanou et al. 2009). In general, signaling pathways that regulate major aspects of seed life have been shown to rely mostly on posttranslational modifications (Arc et al. 2011).

\section{Conclusion}

There is a clear negative correlation between the protein carbonylation level and the germination capacity of beech 
seeds. It can be hypothesized that beech seeds are unable to germinate after long-term storage due to loss of desiccation tolerance and effects on the processes of protein synthesis and native conformation preservation. The proteins associated with response to stress, such as dehydrin, USP, TCP1, RAD23-3, and 14-3-3, might be possible candidates that after carbonylation may decrease the chances of seeds to cope with the stresses associated with natural aging and the environmental stresses that can occur during dormancy release and germination. Based on our results, it can be hypothesized that beech seeds might be unable to germinate after long-term storage due to the loss of desiccation tolerance and affections in the processes of protein synthesis and native conformation preservation. Recent studies unraveled the importance of protein posttranslational modifications in seed dormancy, longevity and vigor indicating a complex interplay between carbonylation and other protein modifications, therefore, more studies are needed in this area to gain a better understanding of the factors that contribute to the modification of protein activities and seed survival upon storage. In particular, the participation of TCP-1 protein in regulation of the proteome dynamics in beech seeds and investigation of possible posttranslational modifications of proteins that were carbonylated specifically in seeds characterized with low germination capacity are in the plan of our interests for the succeeding experiments.

Acknowledgements This research was supported by The Ministry of Science and Higher Education (Poland) grant N0. N309 298039 and performed with the help of the Laboratory of Proteomics (Institute of Dendrology) in which GE Healthcare devices (Multiphor II Electrophoresis System, gel analysis system, Ettan Spot Picker) were purchased with funds provided by grant numbers PO4G 07525 , 3289/PO1/2006/31 of The Ministry of Science and Higher Education (Poland) and The Foundation for Polish Science and Technology Program.

Open Access This article is distributed under the terms of the Creative Commons Attribution License which permits any use, distribution, and reproduction in any medium, provided the original author(s) and the source are credited.

\section{References}

Arc E, Galland M, Cueff G, Godin B, Lounifi I, Job D, Rajjou L (2011) Reboot the system thanks to protein post-translational modifications and proteome diversity: how quiescent seeds restart their metabolism to prepare seedling establishment. Proteomics 11:1606-1618

Bailly C (2004) Active oxygen species and antioxidants in seed biology. Seed Sci Res 14:93-1078. doi:10.1079/SSR2004159

Bailly C, El-Maarouf-Bouteau H, Corbineau F (2008) From intracellular signaling networks to cell death: the dual role of reactive oxygen species in seed physiology. C R Biol 331(10):806-814. doi:10.1016/j.crvi.2008.07.022
Braconi D, Bernardini G, Possenti S, Laschi M, Arena S, Scaloni A, Geminiani M, Sotgiu M, Santucci A (2009) Proteomics and redox-proteomics of the effects of herbicides on a wild-type wine Saccharomyces cerevisiae strain. J Proteome Res 8:256-267. doi:10.1021/pr800372q

Cong Y, Baker ML, Jakana J, Woolford D, Miller EJ, Reissmann S, Kumar RN, Redding-Johanson AM, Batth TS, Mukhopadhyay A, Ludtke SJ, Frydman J, Chiu W (2010) 4.0-A resolution cryoEM structure of the mammalian chaperonin TRiC/CCT reveals its unique subunit arrangement. PNAS 107(11):4967-4972. doi:10.1073/pnas.0913774107

Dalle-Donne I, Giustarini D, Colombo R, Rossi R, Milzani A (2003) Protein carbonylation in human diseases. Trends Mol Med 9(4):169-176. doi:10.1016/S1471-4914(03)00031-5

Denison FC, Paul AL, Zupanska AK, Ferl RJ (2011) 14-3-3 proteins in plant physiology. Semin Cell Dev Biol 22(7):720-727. doi:10. 1016/j.semcdb.2011.08.006

El-Maarouf-Bouteau H, Meimoun P, Job C, Job D, Bailly C (2013) Role of protein and mRNA oxidation in seed dormancy and germination. Front Plant Sci 4:77. doi:10.3389/fpls.2013.00077

Farmer LM, Book AJ, Lee KH, Lin YL, Fu H, Vierstra RD (2010) The RAD23 family provides an essential connection between the 26S proteasome and ubiquitylated proteins in Arabidopsis. Plant Cell 22(1):124-142. doi:10.1105/tpc.109.072660

Gallardo K, Job C, Groot SP, Puype M, Demol H, Vandekerckhove J, Job D (2002) Proteomics of Arabidopsis seed germination. A comparative study of wild-type and gibberellin-deficient seeds. Plant Physiol 129(2):823-837. doi:10.1104/pp.002816

Grune T, Catalgol B, Jung T (2013) Protein oxidation and aging: different model systems and affecting factors. In: Uverski VN (ed) Protein oxidation and aging. Wiley, Inc., Hoboken, New Jersey, pp 295-370

ISTA (1999) International rules for seed testing. Seed Sci Technol 27:1-133 (Supplement)

Job C, Rajjou L, Lovigny Y, Belghazi M, Job D (2005) Patterns of protein oxidation in Arabidopsis seeds and during germination. Plant Physiol 138:790-802. doi:10.1104/pp.105.062778

Kalemba EM, Pukacka S (2008) Changes in late embryogenesis abundant proteins and a small heat shock protein during storage of beech (Fagus sylvatica) L seeds. Env Exp Bot 63(1-3):274-280. doi:10.1016/j.envexpbot.2007.12.011

Kalemba EM, Janowiak F, Pukacka S (2009) The contribution of LEA protein in the acquisition of desiccation tolerance in beech (Fagus sylivatica L.) seeds. Tree Physiol 23(2):305-315. doi:10. 1007/s00468-008-0278-8

Kalisman N, Schröder GF, Levitt M (2013) The crystal structures of the eukaryotic chaperonin CCT reveal its functional partitioning. Structure 21(4):540-549. doi:10.1016/j.str.2013.01.017

Katz A, Orellana O (2012) Protein synthesis and the stress response. In: Biyani M (ed) Cell-free protein synthesis. InTech, Croatia, pp 111-134

Laemmli UK (1970) Cleavage of structural proteins during the assembly of the head of bacteriophage T4. Nature 227:680-685. doi:10.1038/227680a0

León-Lobos P, Ellis RH (2002) Seed storage behaviour of Fagus sylvatica and Fagus crenata. Seed Sci Res 12:31-37. doi:10. 1079/SSR200195

Levine RL, Williams JA, Stadtman EP, Shacter E (1994) Carbonyl assays for determination of oxidatively modified proteins. Methods Enzymol 233:346-357

Loukehaich R, Wang T, Ouyang B, Ziaf K, Li H, Zhang J, Lu Y, Ye Z (2012) SpUSP, an annexin-interacting universal stress protein, enhances drought tolerance in tomato. $J$ Exp Bot 63(15):5593-5606. doi:10.1093/jxb/ers220

Lounifi I, Arc E, Molassiotis A, Job D, Rajjou L, Tanou G (2013) Interplay between protein carbonylation and nitrosylation in 
plants. Proteomics 13(3-4):568-578. doi:10.1002/pmic. 201200304

Magi B, Ettorre A, Liberatori S, Bini L, Andreassi M, Frosali S, Neri P, Pallini V, Di Stefano A (2004) Selectivity of protein carbonylation in the apoptotic response to oxidative stress associated with photodynamic therapy: a cell biochemical and proteomic investigation. Cell Death Differ 11:842-852. doi:10. 1038/sj.cdd.4401427

Maisonneuve E, Ducret A, Khoueiry P, Lignon S, Longhi S, Talla E, Dukan S (2009) Rules governing selective protein carbonylation. PLoS One 4(10):e7269. doi:10.1371/journal.pone.0007269

McDonald MB (1999) Seed deterioration: physiology, repair and assessment. Seed Sci Technol 27:177-237

Møller IM, Sweetlove LJ (2010) ROS signalling-specificity is required. Trends Plant Sci 15(7):370-374. doi:10.1016/j. tplants.2010.04.008

Møller IM, Jensen PE, Hansson A (2007) Oxidative modifications to cellular components in plants. Annu Rev Plant Biol 58:459-481

Møller IM, Rogowska-Wrzesinska A, Rao RS (2011) Protein carbonylation and metal-catalyzed protein oxidation in a cellular perspective. J Proteomics 74(11):2228-2242. doi:10.1016/j. jprot.2011.05.004

Mukherjee A, Lutkenhaus J (1998) Dynamic assembly of FtsZ regulated by GTP hydrolysis. EMBO J 17(2):462-469. doi:10. 1146/annurev.arplant.58.032806.103946

Müller K, Carstens AC, Linkies A, Torres MA, Leubner-Metzger G (2007) The NADPH-oxidase AtrbohB plays a role in Arabidopsis seed after-ripening. New Phytol 184(4):885-897. doi:10. 1111/j.1469-8137.2009.03005.x

Muthuramalingam M, Matros A, Scheibe R, Mock HP, Dietz KJ (2013) The hydrogen peroxide-sensitive proteome of the chloroplast in vitro and in vivo. Front Plant Sci 4:54. doi:10.3389/ fpls.2013.00054

Nyström T (2005) Role of oxidative carbonylation in protein quality control and senescence. EMBO J 24:1311-1317. doi:10.1038/sj. emboj.7600599

Oracz K, El-Maarouf Bouteau H, Farrant JM, Cooper K, Belghazi M, Job C, Job D, Corbineau F, Bailly C (2007) ROS production and protein oxidation as a novel mechanism for seed dormancy alleviation. Plant J 50(3):452-465. doi:10.1111/j.1365-313X. 2007.03063.x

Pickering AM, Koop AL, Teoh CY, Ermak G, Grune T, Davies KJ (2010) The immunoproteasome, the $20 \mathrm{~S}$ proteasome and the PA28 $\alpha \beta$ proteasome regulator are oxidative-stress-adaptive proteolytic complexes. Biochem J 432(3):585-594. doi:10. 1042/BJ20100878

Pukacka S, Ratajczak E (2005) Production and scavenging of reactive oxygen species in Fagus sylvatica seeds during storage at varied temperature and humidity. J Plant Physiol 162:873-885. doi:10. 1016/j.jplph.2004.10.012

Pukacka S, Ratajczak E (2007) Age-related biochemical changes during storage of beech (Fagus sylvatica L.) seeds. Seed Sci Res 17:45-53. doi:10.1017/S0960258507629432

Pukacka S, Hoffmann S, Goslar J, Pukacki PM, Wojkiewicz E (2003) Water and lipid relations in beech (Fagus sylvatica L.) seeds and its effect on storage behaviour. Biochim Biophys Acta 1621(1):48-56. doi:10.1016/S0304-4165(03)00046-1

Rajjou L, Debeaujon I (2008) Seed longevity: survival and maintenance of high germination ability of dry seeds. C R Biol 331(10):796-805. doi:10.1016/j.crvi.2008.07.021
Rajjou L, Lovigny Y, Groot SPC, Belghazi M, Job C, Job D (2008) Proteome-wide characterization of seed aging in Arabidopsis: a comparison between artificial and natural aging protocols. Plant Physiol 148:620-641. doi:10.1104/pp.108.123141

Reiland S, Messerli G, Baerenfaller K, Gerrits B, Endler A, Grossmann J, Gruissem W, Baginsky S (2009) Large-scale Arabidopsis phosphoproteome profiling reveals novel chloroplast kinase substrates and phosphorylation networks. Plant Physiol J 150(2):889-903. doi:10.1104/pp.109.138677

Reznick AZ, Packer L (1994) Oxidative damage to proteins: spectrophotometric method for carbonyl assay. Methods Enzymol 233:357-363. doi:10.1016/S0076-6879(94)33041-7

Seifart Gomes C, Izar B, Pazan F, Mohamed W, Mraheil MA, Mukherjee K, Billion A, Aharonowitz Y, Chakraborty T, Hain T (2011) Universal stress proteins are important for oxidative and acid stress resistance and growth of Listeria monocytogenes EGD-e in vitro and in vivo. PLoS One 9:e24965. doi:10.1371/ journal.pone. 0024965

Smith AG, Johnson CB, Vitha S, Holzenburg A (2011) Oligomerization of plant FtsZ1 and FtsZ2 plastid division proteins. Arch Biochem Biophys 513(2):94-101. doi:10.1016/j.abb.2011.07. 001

Tanou G, Job C, Rajjou L, Arc E, Belghazi M, Diamantidis G, Molassiotis A, Job D (2009) Proteomics reveals the overlapping roles of hydrogen peroxide and nitric oxide in the acclimation of citrus plants to salinity. Plant J 60(5):795-804. doi:10.1111/j. 1365-313X.2009.04000.x

Terskikh VV, Zeng Y, Feurtado JA, Giblin M, Abrams SR, Kermode AR (2008) Deterioration of western redcedar (Thuja plicata Donn ex D. Don) seeds: protein oxidation and in vivo NMR monitoring of storage oils. J Exp Bot 59(4):765-777. doi:10. 1093/jxb/erm357

Testerink C, van der Meulen RM, Oppedijk BJ, de Boer AH, Heimovaara-Dijkstra S, Kijne JW, Wang M (1999) Differences in spatial expression between 14-3-3 isoforms in germinating barley embryos. Plant Physiol 121(1):81-88. doi:10.1104/pp. 121.1.81

Verma DPS, Cheon C-I, Hong Z (1994) Small GTP-binding proteins and membrane biogenesis in plants. Plant Physiol 106:1-6. doi:10.1104/pp.106.1.1

Wade SL, Auble DT (2010) The Rad23 ubiquitin receptor, the proteasome and functional specificity in transcriptional control. Transcription 1(1):22-26. doi:10.4161/trns.1.1.12201

Wang WQ, Møller IM, Song SQ (2012) Proteomic analysis of embryonic axis of Pisum sativum seeds during germination and identification of proteins associated with loss of desiccation tolerance. J Proteomics 77:68-86. doi:10.1016/j.jprot.2012.07. 005

Wong CM, Marcocci L, Liu L, Suzuki YJ (2010) Cell signaling by protein carbonylation and decarbonylation. Antioxid Redox Signal 12(3):393-404. doi:10.1089/ars 2009.2805

$\mathrm{Xu} \mathrm{T}$ (2012) Rho GTPase activity analysis in plant cells plant signalling networks. Methods Mol Biol 876:135-144. doi:10. 1007/978-1-61779-809-2_10

Yacoub A, Kelley MR, Deutsch WA (1996) Drosophila ribosomal protein PO contains apurinic/apyrimidinic endonuclease activity. NAR 24(21):4298-4303. doi:10.1093/nar/24.21.4298 